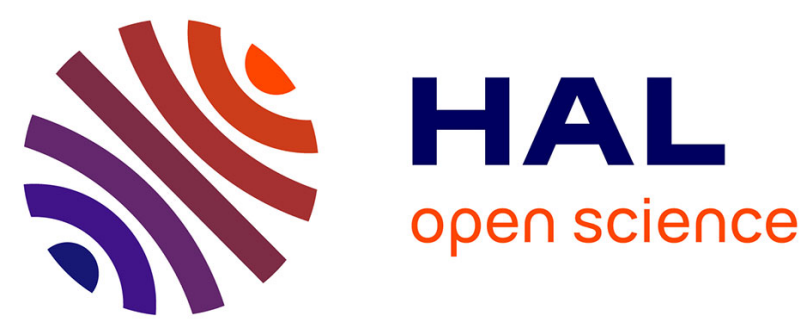

\title{
Comparison of the biodegradable polymer everolimus-eluting stent with contemporary drug-eluting stents: A systematic review and meta-analysis
}

Fabien Picard, Michele Pighi, Quentin de Hemptinne, Juhani Airaksinen, Giulia Vinco, Aurélien de Pommereau, Fausto Biancari, Olivier Varenne

\section{To cite this version:}

Fabien Picard, Michele Pighi, Quentin de Hemptinne, Juhani Airaksinen, Giulia Vinco, et al.. Comparison of the biodegradable polymer everolimus-eluting stent with contemporary drug-eluting stents: A systematic review and meta-analysis. International Journal of Cardiology, 2019, 278, pp.51 - 56. 10.1016/j.ijcard.2018.11.113 . hal-03486920

\section{HAL Id: hal-03486920 \\ https://hal.science/hal-03486920}

Submitted on 20 Dec 2021

HAL is a multi-disciplinary open access archive for the deposit and dissemination of scientific research documents, whether they are published or not. The documents may come from teaching and research institutions in France or abroad, or from public or private research centers.
L'archive ouverte pluridisciplinaire HAL, est destinée au dépôt et à la diffusion de documents scientifiques de niveau recherche, publiés ou non, émanant des établissements d'enseignement et de recherche français ou étrangers, des laboratoires publics ou privés.

\section{(c) (1) $\$$}

Distributed under a Creative Commons Attribution - NonCommerciall 4.0 International 
1 Comparison of the biodegradable polymer everolimus-eluting stent with contemporary drug-

2 eluting stents: a systematic review and meta-analysis

3

4 Fabien Picard, MD, MSc ${ }^{1,2}$; Michele Pighi, $\mathrm{MD}^{3}$; Quentin de Hemptinne, MD ${ }^{4}$, Juhani Airaksinen,

$5 \mathrm{MD}, \mathrm{PhD}^{5}$; Giulia Vinco, $\mathrm{MD}^{3}$, Aurélien de Pommereau, $\mathrm{MD}^{1}$; Fausto Biancari*, MD, $\mathrm{PhD}^{5,7,8}$;

6 Olivier Varenne*, $\mathrm{MD}, \mathrm{PhD}^{1,2}$.

7

$8 *$ : These authors contributed equally as senior author

Affiliations:

11 1: Department of Cardiology, Hôpital Cochin, AP-HP, Paris, France

12 2: Université Paris Descartes, Faculté de Médecine, Paris, France

13 3: Department of Medicine, McGill University Health Center, Montréal, Canada

14 4: Department of Cardiology, CHU Saint-Pierre, Université Libre de Bruxelles, Brussels, Belgium

15 5: Heart Center, Turku University Hospital and University of Turku, Turku, Finland

16 6: Department of Medicine, University of Verona, Verona, Italy

17 7: Department of Surgery, University of Turku, Turku, Finland

8: Department of Surgery, University of Oulu, Oulu, Finland

Address for correspondence: Fabien Picard, Hopital Cochin, Département de Cardiologie, 27 rue du

Faubourg Saint-Jacques, 75014, Paris; Fax: +33 158411666; Phone: +33 158412750; E-mail:

22 Fabien.picard@aphp.fr

$\underline{\text { Running title: Biodegradable polymer everolimus-eluting stent: a meta-analysis }}$

Funding: This research did not receive any specific grant from funding agencies in the public, commercial, or not-for-profit sectors.

Relationship with industry: FP reports consulting fees from Biotronik. OV reports personal fees from Boston Scientific and Abbott Vascular. JA has given lectures for Bayer, Cardiome, Pfizer, Abbott, AstraZeneca and Boehringer Ingelheim. The other authors declare that they have no known conflicts of interest. 


\section{Abstract}

2 Aims: Despite similar efficacy and safety profile in pilot studies, BP-DES could have potential benefit

3 over latest generation DP-DES by facilitating vessel healing, therefore reducing inflammation and

4 neoatherosclerosis leading to enhanced clinical safety. Therefore, we sought to perform a meta-

5 analysis of randomized clinical trials (RCTs) comparing the safety and efficacy of everolimus-eluting

6 BP-DES (BP-EES) to second-generation DP-DES.

7 Methods and results: We conducted a systematic review and meta-analysis to examine the safety and

8 efficacy of BP-EES in patients treated for coronary artery disease. We searched PubMed, Scopus, and

9 the Cochrane Library through February 2018 for RCTs that included outcome data on BP-EES. We

10 identified four eligible studies, which included a total of 4,631 patients. Three studies reported a

11 follow-up of one year and one study of five years. The BP-EES group, included 2,315 patients and the

12 DP-DES group included 2,316 patients (1,143 treated with DP-EES and 1,173 treated with

13 zotarolimus eluting DP-DES). Patient's characteristics were comparable between the two groups

14 except for higher prevalence of prior MI in the DP-DES group (25.7 vs $22.5 \%$, respectively, $\mathrm{p}=0.001$ ).

15 Procedural characteristics were comparable among groups except for slightly longer lesions in the BP-

16 EES group compared to the DP-DES group (mean 15.1 vs $14.9 \mathrm{~mm}, \mathrm{p}=0.04$ ). No significant

17 differences were observed for cardiac mortality ( $\mathrm{p}=0.72)$, occurrence of MI ( $\mathrm{p}=0.64)$, any TLR

$18(\mathrm{p}=0.93), \mathrm{ST}(\mathrm{p}=0.85)$ or major adverse cardiac events $(\mathrm{p}=0.43)$.

19 Conclusion: Overall, based on the available data BP-EES had similar one-year outcomes to 20 contemporary DP-DES. Whether these devices could enhance clinical safety remains to be evaluated 21 at longer follow-up.

24 Keywords: Everolimus; biodegradable polymer; SYNERGY; durable polymer; coronary artery 25 disease 


\section{Abbreviations}

3 BP: biodegradable polymer

4 DES: drug-eluting stent

5 DP: durable polymer

6 EES: everolimus-eluting stent

7 MI: myocardial infarction

8 PCI: percutaneous coronary intervention

9 PRISMA: Preferred Reporting Items for Systematic Reviews and Meta-Analyses

10 PtCr: platinum chromium

11 ST: stent thrombosis

12 ZES: zotarolimus-eluting stent

13

14

15

16

17

18

19

20

21

22

23

24

25

26

27

28 


\section{Introduction}

3 The implantation of a drug-eluting stent (DES) is now considered the standard approach for 4 percutaneous coronary intervention (PCI). ${ }^{1}$ While the addition of a drug-eluting polymer to the 5 coronary stent marked a major advance in reducing restenosis, the lifelong presence of a durable 6 polymer (DP) in a coronary artery induces vessel wall inflammation, delayed arterial healing, and 7 occasionally cause serious complications such as stent thrombosis (ST) and myocardial infarction 8 (MI). ${ }^{2}$ These drawbacks motivated the development of stents with biodegradable coatings that leave 9 only a bare metal stent after polymer resorption and raises the obvious question of whether 10 development of biodegradable-polymer drug-eluting stents (BP-DES) will improve outcomes. ${ }^{2}$ Metal 11 alloy coronary stent platforms with biodegradable polymers are associated with comparable clinical 12 outcomes when compared with newer DP-DES ${ }^{3,4}$. The possible influence of additional factors, 13 including polymer composition and stent strut thickness, ${ }^{5}$ have been topics of debate. ${ }^{6}$ It is important to note that there is significant variability in the strut thickness of available BP-DES, which may partly 15 account for the failure of BP-DES to demonstrate superiority over DP-DES. Today, novel 16 biodegradable polymer stents are available with uncoated struts and up to half as thick as the struts of 17 the first generation BP-DES. ${ }^{2}$ The Synergy ${ }^{\mathrm{TM}}$ stent (Boston Scientific Corporation) is a thin-strut (74$79 \mu \mathrm{m})$ platinum chromium $(\mathrm{PtCr})$ metal alloy stent that elutes everolimus from a bioabsorbable Poly (D,L-lactide-co-glycolide) polymer only applied to the abluminal surface (BP-EES). ${ }^{7}$

The results of the recently published EVOLVE II trial ${ }^{8}$ are encouraging and suggest that PCI with BP-

21 EES or with DP-DES (Promus ${ }^{\mathrm{TM}}$, Boston Scientific Corporation) results in similar outcome. We sought to investigate the efficacy of this BP-EES in the present meta-analysis of randomized controlled trials (RCTs) comparing clinical outcomes of patients treated with BP-EES compared to latest generation DP-DES.

\section{Methods}

27 2.2 Search Methods. MEDLINE, Scopus, and the Cochrane Library database were systematically searched for manuscripts through February 2018. Articles were recorded by using the following search 
1 strategy: "Synergy" OR “everolimus" AND "stent" AND "bioabsorbable polymer" OR "bioresorbable

2 polymer" OR "biodegradable polymer". The systematic review was performed according to the

3 Preferred Reporting Items for Systematic Reviews and Meta-Analyses (PRISMA) Statement ${ }^{9}$. We

4 limited our search to articles published in English. Reference lists of the original papers were retrieved

5 and meticulously hand-searched to identify other relevant studies. This study is registered with

6 PROSPERO, number CRD42018088511.

7 We limited our data to studies on the Synergy ${ }^{\mathrm{TM}}$ stent (Boston Scientific Corporation). We included all

8 RCTs which: 1) examined the use of BP-EES in adult humans, 2) were compared to a durable-

9 polymer DES and, 3) reported on at least one of the following safety and efficacy outcomes: vessel

10 restenosis, ST, target-lesion revascularization (TLR), myocardial infarction (MI), cardiac death, all-

11 cause mortality, and major adverse cardiac events (MACE) or device oriented clinical endpoints

12 (DOCE). Inclusion was restricted to studies published in English. In cases of duplicate publications,

13 the most recent one including the outcomes of interest was selected. We excluded non-randomized

14 studies, animal studies, letters to the editor, editorials, poster or oral presentations, reviews, and

15 studies that did not examine BP-EES as an intervention. Relevant abstracts from conference

16 proceedings were included to provide interim results from ongoing investigations.

2.2 Data Extraction. Two investigators (FP and MP) independently reviewed the studies and reported the results in a structured database. Disagreements between the investigators regarding the inclusion of each trial were resolved by consensus by a third independent investigator (OV). Pre-specified data were extracted from each study including: study design and period, demographic and clinical characteristics of the study population, and duration of the follow-up. Outcomes of interest including cardiac death, MI, TLR, TLF, ST, all-cause mortality, vessel restenosis, and MACE, were extracted as counts and percentages and recorded according the intention-to-treat principle. The quality of the studies included in the present analysis was assessed according to the National Heart, Lung, and Blood Institute (NHLBI) quality assessment tool (https://www.nhlbi.nih.gov/health-topics/study-qualityassessment-tools). 
$1 \quad$ 2.3 Data synthesis and analysis. Baseline risk factors and outcomes are reported as pooled

2 proportions or mean differences with $95 \%$ confidence intervals (CI). The average effects for the 3 outcomes (odd ratios, ORs) and 95\% confidence intervals (CIs) were calculated by using a random-

4 effects method. ${ }^{8}$ Heterogeneity among trials were estimated with $\mathrm{I}^{2}$ statistics $\left(\mathrm{I}^{2}>40 \%\right.$ indicating 5 substantial heterogeneity). Funnel plots were used to test for small study effects. Statistical

6 significance for hypothesis testing was set at the 0.05 level. Statistical analysis was performed using 7 Reviewer Manager version 5.3 (The Nordic Cochrane Centre, The Cochrane Collaboration, 2014) and 8 Open Meta-analyst (http://www.cebm.brown.edu/openmeta/, accessed on March $4^{\text {th }}$, 2018) statistical 9 softwares.

3.1 Search Results. Our search identified a total of 4,180 potentially relevant publications. Following our exclusion criteria, 64 publications were retrieved and evaluated for eligibility. A total of 4 RCTs met our inclusion criteria. ${ }^{7,8,10,11}$ We used the published data with the longest available follow-up. Our study flowchart summarizing the study selection process in accordance with the PRISMA Statement is shown on Figure 1.

These four RCTs were of good quality (Suppl. Tab. 1) according to the NHLBI criteria and included a total of 4,631 patients. Among these patients, 2,315 were randomized to receive a BP-EES, and 2,316 patients to receive a DP-DES (DP-EES $(n=1,143)$ and DP-zotarolimus eluting stent (ZES), $n=1,173)$. The characteristics of these RCTs are presented in Supplemental Tables 1 and 2.

\subsection{Patients and procedural characteristics.}

Baseline patient's characteristics are reported in Table 2. There was no difference in age (pooled mean, 61.7 vs 61.9 years, $\mathrm{p}=0.67)$, male sex ( 71.4 vs $72.8 \%, \mathrm{p}=0.33)$, smoking habit (37.5 vs $40.3 \%$, $\mathrm{p}=0.34$ ), diabetes ( 22.6 vs $23.5 \%, \mathrm{p}=0.84)$, hypertension (60.9 vs $61.3 \%, \mathrm{p}=0.98$ ) or dyslipidaemia (51.0 vs 51.7\%, p=0.36). Patients who received DP-DES had a higher prevalence of prior MI (25.7 vs $22.5 \%, \mathrm{p}=0.001)$ compared to BP-EES. 
1 Procedural characteristics are presented in Table 2. There was no difference among treated vessels

2 ( 46.9 vs $47 \%, p=0.45$ were treated on the left anterior descending artery; 28.0 vs $29.1 \%, p=0.18$ on the

3 left circumflex artery; 37.2 vs $34 \%, \mathrm{p}=0.15$ on the right coronary artery; and 0.7 vs $0.8 \%, \mathrm{p}=0.95$ on

4 the left main coronary artery). Reference vessel diameter, minimal lumen diameter, stenosis diameter

5 and stent length were similar among the study groups, whereas in BP-EES group the treated lesions

6 were slightly longer (pooled mean, 15.1 vs $14.9 \mathrm{~mm}, \mathrm{p}=0.04$ ).

7

\subsection{BP-EES vs. DP-DES on efficacy outcomes.}

9 Study-level outcomes at longest available follow-up for MACE, the individual components of MACE,

10 TLR, and ST are summarized in Table 2 and Figure 2. Three studies reported a follow-up of one year 11 and one study of five years.

12 MACE occurred in $7.0 \%$ of the patients treated with BP-EES and in $6.2 \%$ of the patients treated with DP-EES (OR 1.10, 95\%-CI: 0.87-1.39, $\mathrm{p}=0.43$; heterogeneity: $\left.\mathrm{I}^{2}=0 \%\right)$.

The rate of cardiac death and TLR were also similar for patients treated with BP-EES and DP-DES (OR 0.88, 95\%-CI 0.44-1.77, $\mathrm{p}=0.72$ and OR 0.97, 95\%-CI 0.53-1.79, $\mathrm{p}=0.93$, respectively).

\subsection{BP-EES vs DP-DES on safety outcomes.}

During the follow-up, the rate of definite-or-probable stent thrombosis was similar among both groups ( $0.4 \%$ vs. $0.5 \%$; OR $0.68,95 \%$-CI: $0.28-1.65, \mathrm{p}=0.85$; heterogeneity: $\left.\mathrm{I}^{2}=0\right)$. In addition, target lesion failure and MI were also similar among groups (4.2\% vs 4.6\%; OR 0.90, 95\%-CI: $0.63-1.28$, p=0.95; heterogeneity: $\mathrm{I}^{2}=0 \%$ and $3.3 \%$ vs. $2.8 \%$; OR $1.02,95 \%$-CI: $0.74-1.42, \mathrm{p}=0.64$; heterogeneity: $\mathrm{I}^{2}=$ $0 \%$, respectively). There was no difference in dual antiplatelet therapy duration between BP-EES and DP-DES groups in these studies.

\section{Discussion}

This meta-analysis showed no significant differences in clinical outcomes at one-year follow-up in patients treated with BP-EES or DP-DES. While there was a numerical reduction in definite or 
1 was also no difference in cardiac death, MI, TLR and TLF when comparing the BP-EES with all DP-

2 DES. There was a numerically higher rate of MACE in the BP-EES group, non-significant either.

3 Interestingly, there was a trend for less TVR associated with BP-EES in the EVOLVE study, ${ }^{7}$ while

4 the present meta-analysis of all available RCTs did not show any significant difference among BP-

5 EES and DP-DES. These data, while not demonstrating superiority of BP-EES, suggest that the BP-

6 EES is comparable to contemporary, widely used DP-DES. Furthermore, given the concerns regarding

7 scaffold thrombosis seen with the Absorb $^{\text {TM }}$ (Abbott Vascular) bioresorbable vascular scaffold, ${ }^{12}$ this

8 data does not raise safety concerns for the BP-EES. Indeed, whether metal alloy coronary stent

9 platforms with BP are associated with improved clinical outcomes when compared with newer DP-

10 DES has been a topic of debate ${ }^{6}$ and may be influenced by additional factors, including polymer

11 composition and stent strut thickness. ${ }^{5}$ It is important to note that there is significant variability in the

12 strut thickness of available BP-DES, which may account for the failure of BP-DES to demonstrate

13 improvement over DP-DES. ${ }^{13}$ Today, some new drug coated stents are available with uncoated struts

14 and up to half as thick as the struts of the early BP-DES. ${ }^{2}$ In addition, the benefits of thin struts and BP

15 are appealing and may be very useful in certain clinical scenarios, such as in-stent restenosis or small-

16 vessel PCI. However, the push toward reduction in strut thickness must be tempered against the need

17 to maintain adequate radial support to prevent late lumen loss. Thin struts may reduce the incidence of

18 side branch closure and periprocedural MI.

19 The present meta-analysis is unable to provide information on the potential benefits of bioresorbable

20 versus durable polymers on the reduction of late/very late stent thrombosis. Indeed, three-out-four of

21 the trials included in the study present a follow-up limited to one-year post implantation. Therefore,

22 based on our results no inference can be made on the theoretical advantage of this platform at long-

23 term. Early RCTs as well as meta-analyses suggested that BP-DES were associated with lower rates

24 of late/very late stent thrombosis when compared with either first generation DES or bare metal

25 stents $^{13}$. Conversely, more recent network meta-analyses and observational studies have suggested that

26 the newer generation cobalt chromium $(\mathrm{CoCr})$ and $\mathrm{PtCr}$ durable polymer (polyvinylidene uoride) EES

27 are associated with even lower rates of ST when compared with other durable polymer DES, early

28 biodegradable polymer DES, and bare metal stents. ${ }^{6,14}$ Finally, a large-scale RCT comparison of the 
1 CoCr EES versus the Nobori ${ }^{\mathrm{TM}}$ (Terumo) BP- DES demonstrated similar long-term outcomes for both

2 stents. ${ }^{15}$ These apparent inconsistencies may be partially explained by differences in BP-DES platform

3 design. Both the time course and extent of endothelial stent coverage, as well as the function and

4 maturation of endothelial cells may be influenced by multiple factors, including metal alloy, stent strut

5 thickness, polymer composition, distribution and the time course for polymer bioresorption. ${ }^{5,16}$ These

6 aspects highlight the importance of performing device specific rather than stent class analyses.

7 There are several limitations related to this study. The present meta-analysis is limited to few studies, 8 matching the inclusion/exclusion criteria, which present a considerable difference in size. Therefore, 9 the results of the present work are most likely driven by the EVOLVE and BIO-RESORT trials. While 10 a patient-level meta-analysis could allow a more accurate comparison, our data are limited to a study11 level comparison. Another limitation is the lack of raw or uniform data. Our study demonstrated very 12 low heterogeneity when comparing clinical outcomes among different trials with the use of random13 effects pooling. As we included only RCTs and utilized all available study data, the likelihood of 14 publication bias appears to be low. While a large number of patients $(n=4,631)$ were included in this 15 meta-analysis, the sample size may still be too small to assess minor differences in the occurrence of 16 rare adverse events such as ST. This study does not provide long-term data while DP-DES already 17 have available long-term clinical data. The BP-EES technology is still relatively new. The majority $18(3 / 4)$ of the randomized trials included in the present study collected outcome data at 12 months from the index procedure and only one characterized by a small population (190 patients) provides data at a 20 longer follow-up (five years). Therefore, the results of the present meta-analysis as to be interpret with 21 caution, underlying the need for a longer follow-up to assess the long-term safety and efficacy of BPEES beyond the first year after treatment.

\section{Conclusion}

In conclusion, BP-EES has similar clinical outcomes compared with the latest generation DP-DES at one year follow-up. These results support the safety of the BP-EES in patients undergoing PCI.

27 Further studies, with long-term results are warranted to evaluate whether a reduction in ST could be observed. 


\section{Acknowledgments}

5 None

6

7

8

9

10

11

\section{Legend to figures}

13 Figure 1: Study flowchart which illustrates the study selection process in accordance with the

14 Preferred Reporting Items for Systematic Reviews and Meta-Analyses (PRISMA) Statement.

15

16

17 Figure 2. Forest plots comparing the outcomes of patients undergoing biodegradable polymer 18 everolimus-eluting stent (BP-EES) or durable polymer drug-eluting stents (DP-DES). The forest plots are presented by subgrouping the trials according to their comparator stent. 


\section{References}

1. Windecker S, Kolh P, Alfonso F, Cremer J, Collet J-P, Falk V, Filippatos G, Head SJ, Hamm C, Jüni P, Kastrati A, Kappetein AP, Knuuti J, Landmesser U, Laufer G, Neumann F-J, Richter DJ, Schauerte P, Sousa Uva M, Taggart DP, Stefanini GG, Torracca L, Valgimigli M, Wijns W, Witkowski A, Authors/Task Force Members. 2014 ESC/EACTS Guidelines on myocardial revascularization: The Task Force on Myocardial Revascularization of the European Society of Cardiology (ESC) and the European Association for Cardio-Thoracic Surgery

(EACTS)Developed with the special contribution of the European Association of Percutaneous Cardiovascular Interventions (EAPCI). Eur Heart J 2014;35:2541-2619.

2. Byrne RA, Stone GW, Ormiston J, Kastrati A. Coronary balloon angioplasty, stents, and scaffolds. The Lancet Elsevier; 2018;390:781-792.

3. El-Hayek G, Bangalore S, Casso Dominguez A, Devireddy C, Jaber W, Kumar G, Mavromatis K, Tamis-Holland J, Samady H. Meta-Analysis of Randomized Clinical Trials Comparing Biodegradable Polymer Drug-Eluting Stent to Second-Generation Durable Polymer DrugEluting Stents. JACC Cardiovasc Interv 2017;10:462-473.

4. Iglesias JF, Roffi M, Degrauwe S, Secco GG, Aminian A, Windecker S, Pilgrim T. Orsiro cobalt-chromium sirolimus-eluting stent: present and future perspectives. Expert Rev Med Devices 2017;14:773-788.

5. Palmaz JC, Bailey S, Marton D, Sprague E. Influence of stent design and material composition on procedure outcome. YMVA 2002;36:1031-1039.

6. Kang S-H, Park KW, Kang D-Y, Lim W-H, Park KT, Han J-K, Kang H-J, Koo B-K, Oh B-H, Park Y-B, Kandzari DE, Cohen DJ, Hwang S-S, Kim H-S. Biodegradable-polymer drugeluting stents vs. bare metal stents vs. durable-polymer drug-eluting stents: a systematic review and Bayesian approach network meta-analysis. Eur Heart J 2014;35:1147-1158.

7. Meredith IT, Verheye S, Dubois C, Dens J, Farah B, Carrié D, Walsh S, Oldroyd K, Varenne O, El-Jack S, Moreno R, Christen T, Allocco DJ. Final five-year clinical outcomes in the EVOLVE trial: a randomised evaluation of a novel bioabsorbable polymer-coated, everolimuseluting stent. EuroIntervention 2018;13:2047-2050.

8. Kereiakes DJ, Meredith IT, Windecker S, Lee Jobe R, Mehta SR, Sarembock IJ, Feldman RL, Stein B, Dubois C, Grady T, Saito S, Kimura T, Christen T, Allocco DJ, Dawkins KD. Efficacy and safety of a novel bioabsorbable polymer-coated, everolimus-eluting coronary stent: the EVOLVE II Randomized Trial. Circulation: Cardiovascular Interventions 2015;8:e002372-e002372.

9. Moher D, Liberati A, Tetzlaff J, Altman DG, PRISMA Group. Preferred reporting items for systematic reviews and meta-analyses: the PRISMA statement. J Clin Epidemiol. 2009. p. 1006-1012.

10. Han Y, Liu H, Yang Y, Zhang J, Xu K, Fu G, Su X, Jiang T, Pang W, Chen J, Yuan Z, Li H, Wang H, Hong T, Liu H, Sun F, Allocco DJ, Zhang M, Dawkins KD. A randomised comparison of biodegradable polymer- and permanent polymer-coated platinum-chromium everolimus-eluting coronary stents in China: the EVOLVE China study. EuroIntervention 2017;13:1210-1217.

11. Birgelen von C, Kok MM, van der Heijden LC, Danse PW, Schotborgh CE, Scholte M, Gin RMTJ, Somi S, van Houwelingen KG, Stoel MG, de Man FHAF, Louwerenburg JHW, 
Hartmann M, Zocca P, Linssen GCM, van der Palen J, Doggen CJM, Löwik MM. Very thin strut biodegradable polymer everolimus-eluting and sirolimus-eluting stents versus durable polymer zotarolimus-eluting stents in allcomers with coronary artery disease (BIO-RESORT): a three-arm, randomised, non-inferiority trial. The Lancet Elsevier; 2018;388:2607-2617.

12. Ali ZA, Gao R, Kimura T, Onuma Y, Kereiakes DJ, Ellis SG, Chevalier B, Vu M-T, Zhang Z, Simonton CA, Serruys PW, Stone GW. Three-Year Outcomes With the Absorb Bioresorbable Scaffold: Individual-Patient-Data Meta-Analysis From the ABSORB Randomized Trials. Circulation 2018;137:464-479.

13. Navarese EP, Kubica J, Castriota F, Gibson CM, De Luca G, Buffon A, Bolognese L, Margheri M, Andreotti F, Di Mario C, De Servi S. Safety and efficacy of biodegradable vs. durable polymer drug-eluting stents: evidence from a meta-analysis of randomised trials.

EuroIntervention 2011;7:985-994.

14. Palmerini T, Benedetto U, Biondi-Zoccai G, Riva Della D, Bacchi-Reggiani L, Smits PC, Vlachojannis GJ, Jensen LO, Christiansen EH, Berencsi K, Valgimigli M, Orlandi C, Petrou M, Rapezzi C, Stone GW. Long-Term Safety of Drug-Eluting and Bare-Metal Stents: Evidence From a Comprehensive Network Meta-Analysis. J Am Coll Cardiol 2015;65:2496-2507.

15. Natsuaki M, Kozuma K, Morimoto T, Kadota K, Muramatsu T, Nakagawa Y, Akasaka T, Igarashi K, Tanabe K, Morino Y, Ishikawa T, Nishikawa H, Awata M, Abe M, Okada H, Takatsu Y, Ogata N, Kimura K, Urasawa K, Tarutani Y, Shiode N, Kimura T. Final 3-Year Outcome of a Randomized Trial Comparing Second-Generation Drug-Eluting Stents Using Either Biodegradable Polymer or Durable Polymer: NOBORI Biolimus-Eluting Versus XIENCE/PROMUS Everolimus-Eluting Stent Trial. Circulation: Cardiovascular Interventions 2015;8:e02817.

16. Eppihimer MJ, Sushkova N, Grimsby JL, Efimova N, Kai W, Larson S, Forsyth B, Huibregtse BA, Dawkins KD, Wilson GJ, Granada JF. Impact of stent surface on thrombogenicity and vascular healing: a comparative analysis of metallic and polymeric surfaces. Circulation: Cardiovascular Interventions 2013;6:370-377. 
Table 1. Patients and procedural characteristics.

\begin{tabular}{|c|c|c|c|c|c|c|}
\hline Baseline characteristics & $\begin{array}{l}\text { No. of } \\
\text { studies }\end{array}$ & BP-EES & DP-DES & $\begin{array}{c}\text { Random-effects } \\
\text { Estimates }\end{array}$ & p-value & $\mathrm{I}^{2}$ \\
\hline Age, years & 4 & $61.7(57.8-65.6)$ & $61.9(59.6-64.3)$ & $-0.39,-2.15-1.37$ & 0.67 & $85 \%$ \\
\hline Male & 4 & $71.4(0.70-0.73)$ & $72.8(70.9-64.6)$ & $0.94,0.83-1.07$ & 0.33 & $0 \%$ \\
\hline Smoking habit & 3 & $37.5(12.1-63.0)$ & $40.3(15.4-65.2)$ & $0.93,0.82-1.06$ & 0.34 & $0 \%$ \\
\hline Diabetes & 4 & $22.6(14.4-30.8)$ & $23.5(15.9-31.1)$ & $0.98,0.86-1.13$ & 0.84 & $0 \%$ \\
\hline Hypertension & 4 & $60.9(41.2-80.7)$ & $61.3(0.44-0.78)$ & $1.01,83.5-1.21$ & 0.98 & $41 \%$ \\
\hline Dyslipidaemia & 4 & $51.0(26.1-76.0)$ & $51.7(27.2-76.1)$ & $0.94,0.83-1.07$ & 0.36 & $0 \%$ \\
\hline Prior CABG or PCI & 4 & $30.1(20.2-40.0)$ & $30.1(18.4-41.8)$ & $0.98,0.86-1.11$ & 0.72 & $0 \%$ \\
\hline Prior myocardial infarction & 4 & $22.5(16.0-29.0)$ & $25.7(20.0-31.4)$ & $0.80,0.69-0.92$ & 0.001 & $0 \%$ \\
\hline Unstable angina & 4 & $25.5(16.3-54.8)$ & $36.0(17.6-54.3)$ & $0.93,0.81-1.06$ & 0.26 & $0 \%$ \\
\hline \multicolumn{7}{|l|}{ Treated vessels } \\
\hline LAD & 4 & $46.9(39.8-54.0)$ & $47.0(40.5-53.7)$ & $1.03(0.92-1.16)$ & 0.45 & $0 \%$ \\
\hline $\mathrm{Cx}$ & 4 & $28.0(21.7-34.2)$ & $29.1(24.1-34.0)$ & $0.91(0.75-1.10)$ & 0.18 & $40 \%$ \\
\hline RCA & 4 & $37.2(30.9-43.4)$ & $34.0(24.7-43.4)$ & $1.07(0.89-1.28)$ & 0.15 & $43 \%$ \\
\hline Left main & 4 & $0.7(0.0-1.6)$ & $0.8(0.0-1.7)$ & $0.87(0.51-1.48)$ & 0.95 & $0 \%$ \\
\hline Reference vessel diameter, $\mathrm{mm}$ & 4 & $2.7(2.6-2.8)$ & $2.7(2.6-2.8)$ & $0.01(-0.03-0.04)$ & 0.76 & $0 \%$ \\
\hline Minimal lumen diameter, mm & 4 & $0.8(0.7-0.9)$ & $0.8(0.6-0.9)$ & $0.0(-0.02-0.02)$ & 0.99 & $38 \%$ \\
\hline Total lesion length, mm & 4 & $15.1(14.0-16.2)$ & $14.9(14.0-15.8)$ & $0.5(0.0-0.9)$ & 0.04 & $35 \%$ \\
\hline Stenosis diameter & 3 & $71.4(65.3-77.5)$ & $70.8(65.9-75.8)$ & $0.7(-0.5-1.8)$ & 0.29 & $68 \%$ \\
\hline Stent length, mm & 3 & $27.3(18.6-36.0)$ & $27.3(17.7-36.9)$ & $-0.02(-0.92-0.87)$ & 0.96 & $64 \%$ \\
\hline
\end{tabular}

Values are proportions, mean differences or odds ratios with 95\% confidence intervals (in parentheses). BP-EES, biodegradable polymer everolimus-eluting stent; DP-DES, durable polymer drug-eluting stent; CI, confidence interval; CABG, coronary artery bypass grafting; PCI, percutaneous coronary intervention; LAD, left anterior descending artery; Cx, circumflex artery; RCA, right coronary artery. 
Table 2. Pooled outcomes

\begin{tabular}{|c|c|c|c|c|c|c|}
\hline Outcomes & $\begin{array}{l}\text { No. of } \\
\text { studies }\end{array}$ & BP-EES & DP-DES & Odds ratio $(95 \% \mathrm{CI})$ & p-value & $\mathrm{I}^{2}$ \\
\hline All-cause death & 4 & $1.4(0.6-2.2)$ & $1.1(0.6-1.6)$ & $1.18(0.71-1.97)$ & 0.52 & $2 \%$ \\
\hline Cardiac death & 4 & $0.6(0.3-0.9)$ & $0.7(0.3-1.0)$ & $0.88(0.44-1.77)$ & 0.72 & $0 \%$ \\
\hline Myocardial infarction & 4 & $3.3(1.5-5.1)$ & $2.8(1.4-4.2)$ & $1.02,(0.74-1.42)$ & 0.64 & $0 \%$ \\
\hline TLR & 4 & $1.8(1.2-2.4)$ & $1.8(1.0-2.6)$ & $0.97(0.53-1.79)$ & 0.93 & $36 \%$ \\
\hline TVR & 4 & $2.7(1.6-3.8)$ & $3.6(2.1-5.1)$ & $0.77(0.50-1.19)$ & 0.25 & $26 \%$ \\
\hline Non-TLR TVR & 3 & $1.3(0.2-2.3)$ & $2.1(0.1-3.1)$ & $0.70(0.38-1.30)$ & 0.60 & $0 \%$ \\
\hline Stent thrombosis & 4 & $0.4(0.1-0.6)$ & $0.5(0.2-0.8)$ & $0.68(0.28-1.65)$ & 0.85 & $0 \%$ \\
\hline TVF & 4 & $5.5(4.1-5.9)$ & $6.1(4.8-7.3)$ & $0.90(0.71-1.16)$ & 0.78 & $0 \%$ \\
\hline TLF & 3 & $4.2(3.2-5.3)$ & $4.6(3.3-5.7)$ & $0.90(0.63-1.28)$ & 0.95 & $0 \%$ \\
\hline MACE & 4 & $7.0(4.4-9.6)$ & $6.2(4.5-7.8)$ & $1.10(0.87-1.39)$ & 0.43 & $0 \%$ \\
\hline
\end{tabular}

Values are proportions or odds ratios with 95\% confidence intervals (in parentheses). BP-EES, biodegradable polymer everolimus-eluting stent; DP-DES, durable polymer drug-eluting stent; CI, confidence interval; TLR, target lesion revascularization; TVR, target vessel revascularization; TVF, target vessel failure; TLF, target lesion failure; MACE, major adverse cardiac event. 


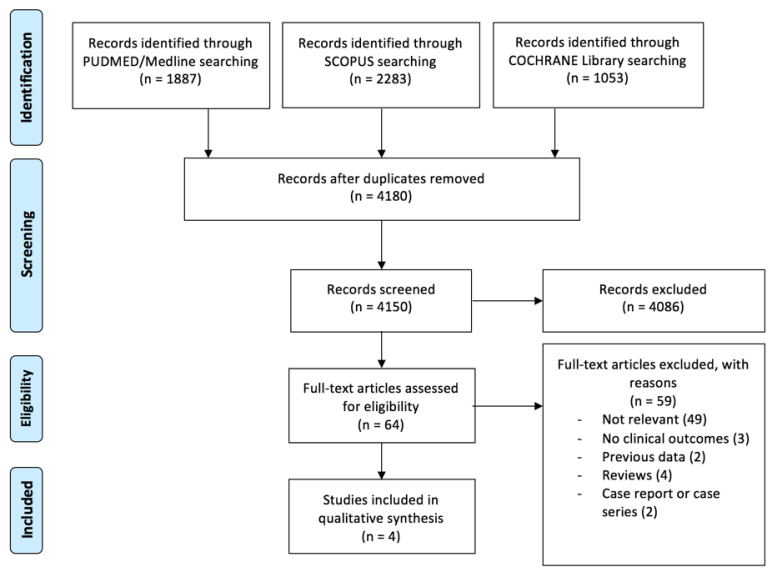


All-cause death

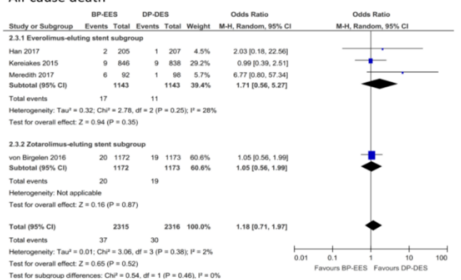

Major adverse cardiac events

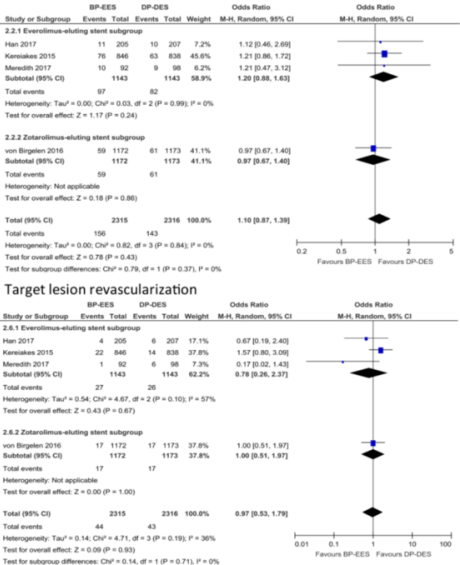

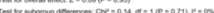

Non-target lesion revascularization target vessel revascularization

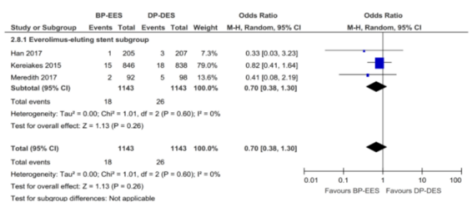

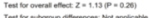

\section{Cardiac death}

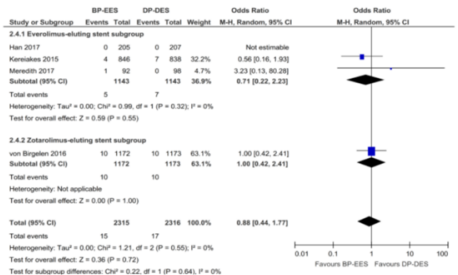

Myocardial infarction

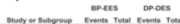

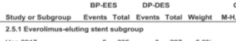

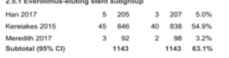

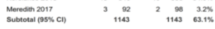

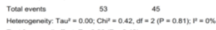

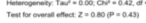

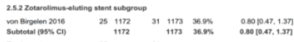

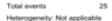

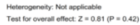

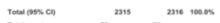

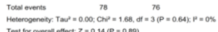

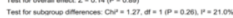

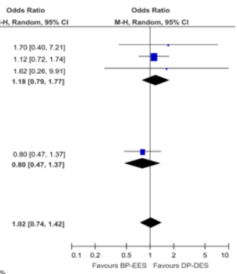

Target vessel revascularization

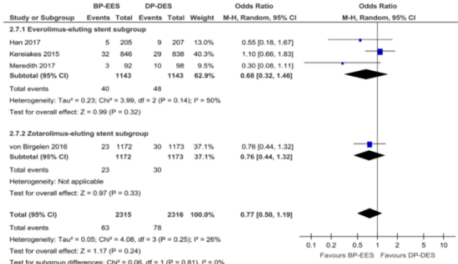

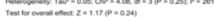

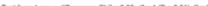

Target lesion failure

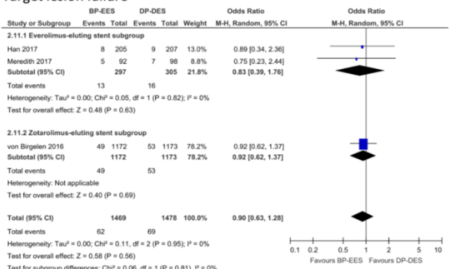

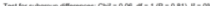

Stent thrombosis

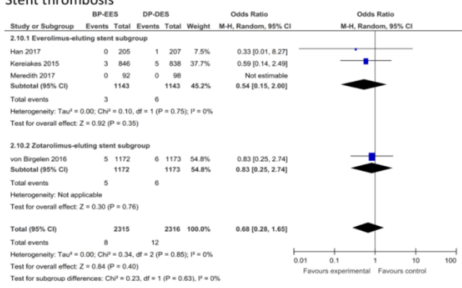

Target vessel failure

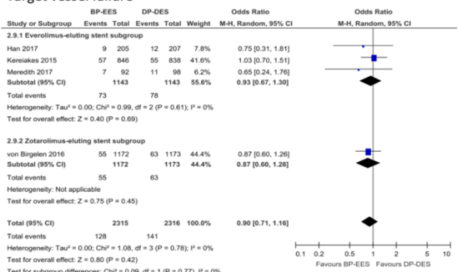

